\title{
Pseudoaneurysm following Fracture shaft of femur - A plea for concern
}

\author{
${ }^{1}$ Dr. Geeta Ahlawat, ${ }^{2}$ Dr. Savita Saini,${ }^{3}$ Dr. Kirti Kshetrapal, \\ ${ }^{4}$ Dr. Mangal Singh Ahlawat, ${ }^{5}$ Dr. sushila Taxak, ${ }^{6}$ Dr. Rajmala Jaiswal \\ ${ }^{1}$ Associate Professor Deptt. Of Anaesthesiology and Critical care,Pt. BDS PGIMS ROHTAK \\ ${ }^{2}$ Senior Professor Deptt. Of Anaesthesiology and Critical care,Pt. BDS PGIMS ROHTA \\ ${ }^{3}$ Associate professor Deptt. Of Anaesthesiology and Critical care,Pt. BDS PGIMS ROHTAK. \\ ${ }^{4}$ Senior Resident Deptt. Of Anaesthesiology and Critical care,Pt. BDS PGIMS ROHTAK. \\ ${ }^{5}$ Professor Deptt. Of Anaesthesiology and Critical care,Pt. BDS PGIMS ROHTAK. \\ ${ }^{6}$ Associate professor Deptt. Of Anaesthesiology and Critical care,Pt. BDS PGIMS ROHTAK.
}

\section{Introduction}

Fracture shaft of femur is one of the common fracture encountered in trauma patients. Blunt injury to the vascular system is rare and has been reported in only $0.3 \%$ of the patients with long bone for requiring hospital admission. We report a case where Pseudoaneurysm was formed around the fracture site, following a blunt injury.

\section{Case Report}

A 45 year old male patient with a three month old fracture shaft of femur following a fall was scheduled for femur plating. He came to the hospital with complaint of pain and swelling around the left hip. There was no significant history except for smoking. On examination respiratory system and cardiovascular system were normal.

All relevant investigations were within normal limits. He was premedicated with tablet alprazolam $0.25 \mathrm{mg}$ a night prior and on the day of surgery. On the operating table, intra-veinous line was secured with 18 gauge cannula and monitors attached. Baseline vital parameters were recorded and under all aseptic precautions, spinal anaesthesia was given with hyperbaric $0.5 \%$ bupivacaine $2.5 \mathrm{ml}$ in sitting position. Once desired level of anaesthesia was achieved patient was positioned to right lateral. Patient was comfortable as surgery commenced. Vitals were maintained.

After about twenty minutes, as soon as bone was exposed and fractured segment manipulated for reduction, sudden gush of blood was seen from the operative site. Severe hypotension followed with blood pressure recorded as $70 \mathrm{~mm}$ of mercury. Another intravenous line was secured with $16 \mathrm{G}$ cannula and intravenous fluids were rushed. Vasoconstrictors were given, but there was no response, steroids as well as colloids showed no improvement. Inotropic support (Inj. Dopamine) was started but blood pressure continued to fall. After 15 minutes, patient became uncomfortable and then drowsy. After juncture, patient was intubated after giving Inj. Ketamine 50mg and Inj. Sexamethomine 50mg. Bleeding still continued. 3 units of blood finished. Packing of the bleeding site was done. Patient condition improved slightly and blood pressure rose to $90 \mathrm{~mm}$ $\mathrm{Hg}$ on inotropes after 15 minutes. Bleeding was partially controlled and plating was done followed by primary closure. Bleeding still persisted from operative site. After about half an hour patient again went into hypotensive shock with blood pressure dropping down to $60 \mathrm{~mm} \mathrm{Hg}$ with inotropes anticipating some vascular injury. Vascular surgeon was now called upon.

Re-exploration by vascular surgeon revealed the source of bleeding to be a Pseudoaneurysm around the fracture site, formed by the profunda femoris branch of the femoral artery. This was carefully ligated and fracture site cleared off the collection. Patient condition improved gradually and a blood pressure of $110 \mathrm{~mm}$ $\mathrm{Hg}$ with inotropes was recorded after half an hour.

Post-operatively, after observing the patient for 30 minutes on the operating table, he was shifted to the intensive care unit with inotropes and put on ventilator support. His condition improved progressively. Inotropes were tapered off and extubated after six hours. Thereafter, patient remained comfortable.

\section{Discussion}

Femur fractures isolated or associated with other injuries are one of the most frequently encountered fractures for repair surgeries. Young males have the higher incidence with commonest mode of injury being road traffic accidents. If the fracture is uncomplicated and patient does not have any co-morbid pathology, spinal anaesthesia is the preffered choice. 
Generally, penetrating injuries were known to be associated with vascular injuries, blunt injuries may also be associated with the same. They are easy to miss because the orthopaedic surgeon as well as anaesthetist have a low index of suspicion for femoral or any other vascular injury associated with such fractures.

Thus, the early recognition of such injuries after blunt trauma in addition to new surgical techniques can lead to dramatic improvement in the outcome for injured limbs. Physical examination is the most expedious and accurate way to determine the presence of an arterial injury by an absent or feble pulse. However, a pseudoaneurysm cannot be ruled out by this, as distal pulses may not be disturbed by its presence, as in this case. Increase in the girth of the limb around the fracture site should arouse the suspicion of pseudoaneurysm.

Moreover in this case:-

-sharp edge of the fractured femur surrounded by soft tissue swelling around the fracture site on X-ray hip (confused to be a usual haematoma);

- increased girth of the thigh around the fracture site,

- Delay in surgical intervention should have aroused the clinical suspicion of pseudoaneurysm.

Hence a sequence of detailed history, careful physical examination and study of relevant investigation profile e.g. X-ray of the fractured site should be adopted. Angiography is the gold standard for confirming the diagnosis of a pseudoaneurysm. Preoperative knowledge of the presence of a pseudoaneurysm would certainly help us to plan an appropriate anaesthetic management. General anaesthesia should be given, additional large bore i.v. line established anticipating the possibility of severe hypotension and shock.

In conclusion, vascular injuries as rare as a pseudoaneurysm should be ruled out before taking up closed long fractures under regional anaesthesia.

\section{References}

[1]. Kluger $Y$ et al, Blunt vascular injury associated with closed mid shaft femur fracture; J.Trauma, 1994 Feb;36(2):222-5

[2]. Dichristina DG et al; Femur fracture with arterial injuries in blunt trauma: J Orthop Trauma, 1994 Dec;8(6):494-503. 